\title{
RITTER'S EXFOLIATIVE DERMATITIS OF THE NEWBORN
}

\author{
By Theodore JAmes
}

The Duchess of York Hospital for Babies, Manchester

The literature on exfoliative dermatitis of the newborn, first described by Ritter von Rittershain in 1878 , is meagre and almost all of the papers have been reports of sporadic cases which suggested a cause or were remarkable for recovery after some one or other method of treatment. What appears to be the extremely uncommon occurrence of the malady in Britain is supported by the fact that Hallez (1932) could not find a case report in the British literature up to 1925 . Since 1925 I have been able to find only two papers by British authors. Bell and Woods (I 942) reported a case satisfactorily treated with sulphapyridine; Bell mentioned that he had come across two other cases of typical Ritter's disease. MacGillivray in the same year published two cases in his care that recovered after proseptasine therapy.

A survey of the literature gave rise to the question whether or not the few cases reported in Britain are a true reflection of the actual incidence in this country. All dermatologists and paediatricians are aware of this peculiar disease, but the published work shows disagreement over the identity of the disease, so that it can be assumed that the disorder has been and still is being diagnosed as a variant of pemphigus neonatorum. Ever since Behrend in 1880 denied Ritter von Rittershain's claim to a new disease different views of its nosology have been expressed.

Since Ritter von Rittershain's full account of his observations made on 297 patients admitted to a foundlings asylum in Prague; there has not been a series remotely comparable with his. Ritter von Rittershain's convictions, evolved from so many cases under his care, should carry more weight than impressions derived from prominent features in a few patients.

A relevant point is that as a result of Ritter von Rittershain's description of a disease unrecognized until he made known his observations, the condition was looked for retrospectively. Although it was found in this way Hallez (1932) in the French literature could discover only seven that had adequate diagnostic criteria. Against this Ritte. von Rittershain's figures had shown a high frefic quency of the illness in Central Europe. His 297 cases were collected from I868 to the end of the first half of 1878 , and averaged 30 a year in his own experience. Nevertheless by 1932, whero Hallez wrote, the incidence in Central Europe appeared to be decreasing and this he attributed to improved hygienic environment. On the other hand there is no evidence that in countries with के low standard of sanitation, dermatitis exfoliativa neonatorum is anything but rare.

Dermatitis exfoliativa' neonatorum, or Ritte' disease, is not specially or separately tabulated the Registrar-General and so his medical statisteas returns do not help to give any idea of the in cidence of the disease in England and Walesy Perhaps (this is proposed with considerable re serve) an inkling may be got from the mortalit figures for pemphigus neonatorum (which is tabulated separately) for there are those who re gard Ritter's disease as essentially a malignan form of pemphigus in the newborn. The mors tality returns for pemphigus neonatorum for thes years 1938 to 1949 inclusive are given in Table

MORTality from Pemphigus NeONatorum For the Years 1938-40 INCLUSIVE

$\begin{array}{llllllllllll}1938 & 1939 & 1940 & 1941 & 1942 & 1943 & 1944 & 1945 & 1946 & 1947 & 1948 & 1948\end{array}$ $\begin{array}{llllllllllll}69 & 41 & 73 & 70 & 67 & 69 & 64 & 39 & 40 & 38 & 17 & 7\end{array}$

Table I discloses that during the years $193 \frac{2}{2}$ to 1944 inclusive, the annual mortality from pemo phigus neonatorum was statistically constantu and that from 1945 to 1947 inclusive there was sudden falling off in the mortality to less than 608 per cent. This sudden and striking fall was re peated to about the same extent in 1948 and again in 1949, so that today the mortality is negligibs compared with what it was in 1944 and the preceding years. There can be little doubt that this improvement in the prognosis is due to moder 
antibiotic therapy. Alongside this improvement in the mortality from pemphigus neonatorum come reports from widely separated countries of cases of Ritter's disease which have responded well to treatment by antibiotics and chemotherapy. A number of these reports have been published for this reason alone, because untreated Ritter's disease is so fatal.

Among the records of the Duchess of York Hospital for Babies I have found Io cases of Ritter's disease. The first case was admitted to the hospital in r934.

Controversy persists over the exact nature of exfoliative dermatitis of the newborn. When Behrend contended in 1880 that the disease which Ritter von Rittershain claimed to have discavered was simply a variation on the so-called Cazanave's pemphigus foliaceus which had first been described in the early I 800 , Ritter von Rittershain devoted a special paper to a vigorous refutation of such a contention ( 1880 ). This refutation was intended to clinch the matter. It did no such thing. Certain authors have engaged themselves on one side or the other of this controversy.

Confusion was made worse when Ferri (1928) and Leiner (1929) found it necessary to differentiate once again the skin disease erythrodermia desquamativa, also known as Leiner's disease, from Ritter's dermatitis exfoliativa. About this time an equally vigorous argument raged over these two diseases as had endured over Ritter's dermatitis exfoliativa and pemphigus neonatorum. In each argument the protagonists were constrained to describe anew the characteristic features of the diseases and to deny the diagnostic criteria of their opponents.

Leiner (1929) denied the reported cases of pemphigus neonatorum which had transformed into Ritter's disease and vice versa. But the next year Goedhart described Ritter's disease going over into pemphigus neonatorum.

Hallez's review of the cases in the French literature, seven in number, gives a detailed differentiation of Leiner's disease from Ritter's to support his reasoning against the unitary concept of the two skin affections.

\section{Aetiopathogenesis and Symptomatology}

Ritter von Rittershain believed the exfoliative dermatitis he described to be one of the different ways in which pyaemia in the newly born could manifest itself. He was convinced that the illness was bacteriogenic. Leiner also believed it to be primarily infective in origin and in his paper dealing with the differentiation of Ritter's dermatitis from his own erythrodermia desquamativa he expressed his view that Ritter's dermatitis is the malignant form of contagious pemphigus neo- natorum which has special features. But there are authors who believe the primary cause is a toxic degeneration of the skin which invites a secondary staphylococcal infection and Ferri (1928) reports two cases of Ritter's disease in which infection of the skin was not present. In one extremely severe case admitted a few hours after birth to the Duchess of York Hospital for Babies infection of the skin could not be proved.

Aetiological hypotheses which have been propounded include a pathological expression or exaggeration of the normal neonatal exfoliation or peeling (Winternitz, 1898), a hereditary form of epidermolysis bullosa (Kaposi, I887), a nutritional disturbance of the superficial layers of the skin (Caspary, I 884), a temporary dysfunction of the endocrine system (Sano, 1943), a primary avitaminosis (Schwartzman, Dragulsky and Rook, 194I), a fundamental deficiency of the skin and mucous membranes (Widerman, 1945) and a diffuse peripheral vascular lesion (Skinner, r910). These diverse hypotheses give some idea of the ignorance which for long has prevailed over the origin of the disease process.

An article by Govan, Cotton and Rydeen (1950) deserves special mention. Eighty infants were exposed over a period of four weeks in a naval nursery for the newborn to a baby with a skin eruption. Within Io days 20 of the infants born in this institution were suffering from a similar skin disease. Throat swabs from the affected infants were cultured and 17 showed a non-haemolytic staphylococcus albus, two a Friedlander bacillus and haemolytic streptococcus, and one a gram-negative diplococcus. Culture of organisms from the infants' skins produced staphylococcus albus in pure growth in 18 and staphylococcus albus predominating in two. Blood from each infant was cultured, but all cultures were negative. Cultures of organisms from the throats of the staff and all nursery hands (20) showed nine of them to be harbouring organisms which had been recovered from the infants. Of the 20 infants with skin lesions, four satisfied the criteria for Ritter's disease and the other 16 cases could be separated into those with vesicles coalescing, rupturing and leaving large areas of exfoliation, those with large discrete bullae, and those with multiple tiny vesicles and pustules. These authors, therefore, had every reason to conclude that Ritter's disease represents merely a severe reaction to a bacterial invader.

As a brief comment on the foregoing, a statement by Warthen and Sherburne (1948) may be mentioned. Several disease entities, including Ritter's, Leiner's, Savill's and pemphigus neonatorum, they said, may exhibit almost identical skin lesions. 
The clinical features which determine the diagnosis of Ritter's disease are constant, but in any one case there may be other and added means of recognition. Ritter von Rittershain noted that the malady began usually to show itself on the face as a scarletiniform erythema, which was often preceded by a fine desquamation which very quickly became generalized over the whole body. There is a tendency for vesicles or bullae to form and these may coalesce and extend rapidly over the whole skin surface. A total exfoliation of the epidermis, with or without bullae formation, gives the infant a scalded or boiled appearance. The eyelids alone may be oedematous and discharge matter or the whole dermis may be turgid with fluid. Although it is usual for the first sign, erythema, to appear in the region of the mouth or chin, rarely this sign may be on the neck, shoulders, thorax, or even hand. Inclusion of the whole skin by the erythema always happens within two or three days. Often the time is a few hours. The skin varies from a scarletiniform redness to purple. At this stage, even without vesicle or bullae formation, the epidermis flakes off with ease, the lightest pressure being enough to separate the epidermis from the underlying corium. Where the epidermis has come away the underlying dermis is red, as though the child had been burned or scalded over these areas. The exfoliation begins soon after the erythema and often before the erythema has covered the body. This exfoliation may come away in large sheets of epidermis, under which the dermis may be wet or dry. Frequently the epidermis leaves the digits like the fingers of a glove. Bullae may hold serous or purulent fluid.

The mucosae of the mouth may or may not be affected by small vesicles; stomatitis, rhinitis or even corneal lesions may be present. The mucocutaneous junctions about the mouth are often fissured and have some resemblance to syphilitic rhagades. About the joints there are often red linear fissures where the epidermis has been removed. Oedema of the skin may appear as a turgidness or be so great as to swell the baby like a bladder.

When the exudation is extreme it is wise to regard the state of the skin with its loss of fluid and protein (Leiner) as an urgent call for the restoration of fluid and nitrogen balance as in a case of burns.

Ritter von Rittershain based his detailed description of the disease on 297 cases seen over ten years. The mortality was 48.8 per cent. When the infant recovers the skin pales gradually and the exfoliation stops gradually. Eventually the skin gets a normal colour.

In the blood the eosinophils are infrequently increased, and a mononucleosis is common in the uncomplicated case. Fever is absent unless in£ fection be present. Infection may take the form of subcutaneous abscesses, other pyodermias, gan grene, septicaemia or bronchopneumonia. If the. baby lives the disease may last seven to ten days or a month or two.

\section{Conclusions}

Four reasons why Ritter's disease and pem $\mathbb{\mathbb { Q }}$ phigus neonatorum should be classed as the same disease were given by Wieland (1923) and may be summarized as follows: A. case of pemphigus neonatorum may pass into the exfoliative dermatitis; pemphigus neonatorum and Ritter' disease do concur in one community; the organisms isolated from the skin in the two types. of lesion are bacteriologically identical and the histopathological changes in the skin of the two conditions are identical. In 1932 Aspergedo described a case of Ritter's disease passing into pemphigus neonatorum.

Before the advent of chemotherapy and the antibiotics the mortality from Ritter's disease was very high; today cases are cured by chemo therapy and antibiotherapy which supports the contention that the cause is essentially infective. and so points to its identity with bullous impeegge and pemphigus of the newborn. But the use of these remedies to overcome the infection preseng in a patient is almost equivalent to their use prophylactically as in the cases where infectio has not been evident. It is the infecting organisro that is chiefly responsible for killing the baby, but it cannot be logically accepted that what kills the infant causes the disease.

The writer had hoped to show a parallel decline in the mortality from pemphigus neonatorum and Ritter's disease following the coming of the new therapeutics, but had this been possible it woule have suggested a common aetiology and patholog. Because a pathogenic organism like the $S$. aurew is practically a commensual with the newbore whose epidermis is so susceptible to infection, the fact that pyogenic bacteria have so frequently bees cultured from the skin lesions of Ritter's disease is not to be taken as incontrovertible proof that the are the cause of the disease. There is better reason to believe that these organisms are almost in stantaneous invaders once the disease has beguefer In cases which are seen very early and over whidg prophylactic umbrellas of antibiotics are raise $\phi$ the disease should run its course to a satisfactody end if no insensitive pathogenic bacteria makf contact. Where infection takes a firm hold, death will almost inevitably follow. Whereas we may not be able to prevent Ritter's disease, we may these days induce a cure. 


\section{BIBLIOGRAPHY}

ASPERGER, H. (1932), Arch. f. kinderheilk., 97, 167. BEHREND, G. (1880), Ibid., $1,138$.

BELL, D., and WOODS, A. W. (1942), Arch. Dis. Childh., 17, 157. CASPARY, J. (1884), Arch. Dermat u. Syph., 16, 122.

FERRI, U. (1928), La Pediatria, 36, 843.

GOEDHART, C. (1930), Nederl. Tijdschr. $v$. geneesk., 74, 5147. GOVAN, C. D., COTTỎN, A. L., and RYDEEN, J. O.'(1950), U.S. Armed Forces M.尹., x, 682 .

HALLEZ, G.-L. (1932), Nourrisson, 20, 270.

KAPOSI, M. (1887) cit. Govan et al.

LEINER, C. (1929), Monatschr. f. kinderheilk., 62, 331.

MACGILLIVRAY, A. G. (1942), Brit. med. F., ii, 340.

RITTER vON RITTERSHAIN, G. (1878), Centralzt.f. kinderheilk., 2, 3
RITTER VON RITTERSHAIN, G. (1880), Arch. kinderheilk., r, 53.

SANO, M. E. (1943), F. Pediat., 23, 280.

SCHWARTZMAN, J., DRAGULSKY, D., and ROOK, G. (1941), Am. F. Dis. Child., 62, 352.

SKINNER, E. F. (1910), Arch. Dermat. and Syph., 22, 75.

vaN VONNO, N. C. (193I), Nederl. Tijdschr. v. geneesk., 75, 1932.

WARTHEN, R. O., and SHERBURNE, J. C. (1948), ₹. Pediat., 3B, 717 .

WIDERMAN, A. (1945), Am. F. Dis. Child., 70, 329.

WIELAND, E. (1923), Ergeb. d. Inneren Med. u. kinderheilk., 24, 47. WIENER, A. S. (1947), New York St. M.Ұ., 47, 1796. WINTERNITZ, R. (1898), Arch. Dermat. u. Syph., 44, 397.

ZAKON, S. J. (1931), Arch. Dermat. and Syph., 24, 830.

\section{THE POSTGRADUATE}
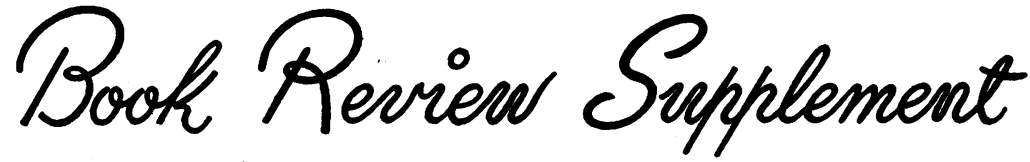

\section{CHEMICAL INDUCTION OF CANCER}

By George Wolf, B.Sc., D.Phil. Pp. xiii +250 , with 5 illustrations. London: Cassel \& Co., Ltd., 1952. 17s. 6d.

This is a book which, as the title indicates, deals with the experimental production of cancer by purely chemical means, i.e., through the intervention of chemical compounds of, for the most part, known chemical constitution whose chemical formulae are depicted. To the discerning chemist with an eye to equating chemical constitution with carcinogenic activity, the work is particularly appealing in the wealth of structural formulae scattered throughout its pages. The author has succeeded in surveying the subject in a comprehensive, authoritative and not over-elaborate way, so that the result is a short and lucid presentation of the facts.

There are five main sections; the structure and activity of tumour-inducing compounds; the biological aspects of tumour induction, as seen in tumour characteristics and pathology, sex differences, hereditary differences, species differences, age and diet; test methods, notably the mode of administration, dosage, latent period, tumour incidence and carcinogenic index; theories of the mode of action of cancinogens; biogenetic relationships; and a final section on the metabolism of carcinogenic hydrocarbons, azo-compounds, aromatic amines and derivatives.

The book is indexed both according to authors and subject matter, thereby facilitating reference. While appealing perhaps specially to the research worker, the thoughtful information packed in the pages of the book will make it fascinating alike to the interested doctor and the enlightened layman. As Professor Haddow puts it, the book will be ' welcomed by those wishing to acquaint themselveso without too great difficulty, with a field of research which, if it has of necessity developed along highlo specialized lines, is nevertheless of the utmost im? portance towards the ultimate solution of the greatest problem confronting medicine.'

The book is attractive in presentation and written in a clear and easily comprehensible style. Moreover, it is moderately priced.

A.C.

\section{THE STORY OF THE ADAPTATION SYNDROME}

By Hans Selye, M.D., Ph.D., D.Sc., F.R.S.(C.)• Pp. 225, illustrated. Montreal: Acta Inc. Medical Publishers. 1952. \$4.50.

Professor Selye tells in this volume how he conceived the idea that a group of apparently unrelated physiological changes, evoked by a variety of stimuli, were part of a common response which he has called the General Adaptation Syndrome. He tells, also, how he has come to believe that a relationship exists between this common response and a variety of diseases in man. The author truly states that in this volume there is no pretence either at objectivity or at completeness. Because of this, and the avowedly informal style, the book cannot be recommended to those wishing seriously to appraise Professor Selye's hypotheses. It provides, however, an easy means whereby the uninitiated may approach the author's larger work with its 8,000 odd references. 